\title{
Are International Asthma Guidelines effective for low-income Brazilian children with asthma?
}

\author{
A.L.B. Cabral*+, W.A.F. Carvalho*, M. Chinen*, R.M. Barbiroto*, F.M.V. Boueri+, M.A. Martins ${ }^{+}$
}

Are International Asthma Guidelines effective for low-income Brazilian children with asthma? A.L.B. Cabral, W.A.F. Carvalho, M. Chinen, R.M. Barbiroto, F.M.V. Boueri, M.A. Martins. OERS Journals Ltd 1998.

ABSTRACT: The present study was designed to evaluate the effectiveness of International Asthma Guidelines in low-income asthmatic children in the city of São Paulo, Brazil.

Fifty children with moderate or severe asthma were evaluated. Patients were evaluated before and after a $1 \mathrm{yr}$ follow-up period using a pre- and post-education design with patients acting as their own controls. Parents were interviewed before and $1 \mathrm{yr}$ after the programme.

Most of the children were receiving inadequate medical care from their primary physicians, based mainly on bronchodilators. After the educational programme combined with a medical treatment based mainly on inhaled steroids, there was a decrease in emergency room visits and no need for hospital admissions. There was also a significant decrease in asthma severity and impairment scores $(\mathbf{p}<0.0001)$. The combination of good medical care and an educational programme can reduce the symptoms of asthma and significantly increase the quality of life, as well as decreasing the costs of asthma treatment.

We conclude that by applying the International Asthma Guidelines substantial success was achieved, resulting in moving the patients from crises-orientated management into a chronic care and preventive management mode. Eur Respir J 1998; 12: 35-40.
*Pulmonary Pediatric Division, Darcy Vargas Hospital, and +Depts of Medicine and Pathology, Faculty of Medicine, University of São Paulo, São Paulo, Brazil.

Correspondence: M.A. Martins, Dept de Clínica Médica, Faculdade de Medicina da Universidade de São Paulo, Av. Dr. Arnaldo 455, 01246-903, São Paulo, SP Brazil, Fax: 55118830827

Keywords: Asthma, asthma treatment, educational programme, quality of life

Received: July 281997

Accepted after revision March 201998

Presented in part at the International Meeting of the American Thoracic Society in Seattle, 1995.

Supported by the following Brazilian scientific agencies: Fundação de Amparo à Pesquisa do Estado de São Paulo (FAPESP), Conselho Nacional de Desenvolvimento Científico e Tecnológico (CNPq), Programa de Núcleos de Excelência (PRONEX-MCT) and Instituto dos Laboratórios de Investigação Médica do Hospital das Clínicas da Faculdade de Medicina da Universidade de São Paulo (LIM-HCFMUSP).
Asthma is the most common chronic disease of childhood and its prevalence and severity seem to be increasing, especially among children [1-5]. The social and economic impact of asthma is enormous, owing not only to healthcare costs but also to lost productivity. Asthma is a leading cause of school absenteeism and one of the primary reasons for hospitalization of children [6-8]. Hospitalization rates and asthma-related mortality are increasing among persons aged $<25$ yrs [9]. Furthermore, it impairs quality of life since many asthmatic children, fearing symptoms, avoid physical exertion and miss many recreational opportunities and other activities essential for normal development.

Many guidelines for the diagnosis and management of asthma have already been published but only the implementation of such guidelines is likely to change this situation. There has also been an increasing interest in improving self-management of asthma through patient education. However, the majority of published paediatric selfmanagement programmes deal with English-speaking, middle-class children [10-12]. When evaluating an asthma self-management programme for low-income Latino children, LEwIs et al. [13] found substantial problems such as poor recognition of the seriousness of the disease and sig- nificant barriers to access and continuity of medical care. However, they found fewer cultural problems when transferring a programme from middle-class white to middleclass Latino audiences.

CLARK et al. [14] also worked with children from a low-income, urban environment. One year after the beginning of the programme, they were able to demonstrate a significant decrease in emergency-room use and hospitalization only in those children who had been hospitalized during the preceding year.

The purpose of the present study was to evaluate the effectiveness of an educational programme combined with good medical care such as that proposed by the International Asthma Guidelines, targeted at asthmatic children from a low-income, urban environment followed in a community hospital outpatient setting. The programme was designed to assist children from disadvantaged communities and to be realistic about the costs for public healthcare. The goals of the educational programme were to improve knowledge about asthma and metered dose inhaler (MDI) techniques, to reduce the use of emergency healthcare resources, to increase compliance with treatment and to improve quality of life. 
This educational programme is integrated into continuing medical care, since even a very good educational programme can never compensate for inadequate medical care. To demonstrate the potential impact of educational intervention it is necessary to have a control and an experimental group, ensuring that both receive adequate medical care. However, children from low-income families lack more than the prescription and provision of appropriate medications. They have difficulties in dealing with issues regarding housing, using the medications with proper techniques and following an action plan given to them. As stated by LewIs et al. [15] "researchers conducting randomized trials involving poor children should be aware of the potential ethical problems inherent in such ventures".

\section{Methods}

The present study involved patients referred by their paediatricians to the asthma clinic of Darcy Vargas Hospital, in the city of São Paulo, Brazil. Fifty children with a diagnosis of moderate or severe asthma were randomly selected at the time of the first visit. Asthma was classified as mild, moderate and severe according to the International Consensus Report on Diagnosis and Treatment of Asthma, 1992 [16]. Patients and parents gave informed consent and the study was approved by the local ethics committee.

Patients were evaluated before and after a 1 yr followup period using a pre-education and post-education design with patients acting as their own controls. Parents were interviewed twice (immediately before and $1 \mathrm{yr}$ after the education programme). The interviews were performed by a research associate who was not involved in the education programme. The majority of interviews took place with the mothers.

The questionnaire of ROSIER et al. [17] was modified to assess the level of severity of asthma (asthma severity score). Ten questions were asked in order to assess the number of hospital admissions, number of acute emergencyroom visits, frequency of symptoms (three questions), intensity of asthma attacks (four questions) and level of impairment (one question). The overall severity score could range between 0-42. Questions and scores are shown in Appendix I.

To evaluate the level of asthma impairment (asthma impairment score), a list of 13 activities in which some asthmatic people are limited was read to the parents (play, play with pets, run, walk, walk uphill, bicycle, play sports, go to cinema, travel, camp, shop, sleep outside, go to parties). They were asked to identify the activities in which their children were not limited at all (score 0), somewhat limited (score 2), very limited (score 4) and totally limited (score 6). The overall impairment score could range between 0-78.

To assess the level of knowledge about asthma, seven questions were asked of the parents to determine the level of factual understating of asthma, its treatment, control and avoidance of precipitants (Appendix II).

In order to check proper inhaler techniques, the children were asked to take two puffs of their inhalers. Their technique was judged using the eight steps of the recommendations of the National Institutes of Health (NIH) review committee for the treatment of asthma [18]. If the child performed the eight steps correctly, they received a score of 10; one incorrect step corresponded to a score of 5 and two or more errors corresponded to a score of 0 .

Patients and parents attended six $1 \mathrm{~h}$ sessions separately. The interval between sessions varied according to the child's asthma severity and the sessions took place on the same days as medical appointments. They were interactive sessions aiming to improve knowledge about the disease (definition of asthma and asthma attack, early warning signs and triggers), medication, MDI technique, devices and environmental control. The action plan was central to the entire programme and involved parents or care-givers assuming greater responsibility for their children's health (Appendix III). Each visit to the hospital was also an opportunity to assess, teach and improve self-management skills and MDI techniques. Children's classes were limited to five per group and parents' classes were limited to 10 per group. These sessions were held in small groups so that participants could discuss their beliefs and fears, share concerns and receive mutual support.

The educational programme began immediately after the first visit to the asthma clinic and was integrated into continuing medical care. Each office visit, although brief, was considered to be an opportunity to provide health education for the child and their parents. The child's involvement in self-care is important, and a persistent dependence on the parents or the healthcare system is counterproductive. Both parents and children talked at each visit with a nurse-educator.

As the educational needs of the patients may change over time, they were reassessed at regular intervals (every visit to the doctor). Periodic evaluation of the MDI technique was also performed to maintain proper use and maximize its usefulness, and the importance of optimal inhalation technique was emphasized to the patient and parents at each visit.

Values for asthma impairment score and asthma severity score before and after the educational programme were compared using the Wilcoxon signed rank test. A p-value $<0.05$ was considered statistically significant.

\section{Results}

All 50 children selected to participate completed the trial. Table 1 shows the sex, age range and asthma severity of participants. Seventy-eight per cent of the children had severe asthma at the time of enrolment in the study.

Although the children studied had moderate or severe asthma, they were being treated mainly with oral $\beta_{2}$-agonists (94\%) and oral theophylline (66\%) (table 2). Only $30 \%$ received regular preventive therapy before the study: ketotifen $(16 \%)$, chromoglycate $(8 \%)$ and inhaled steroids $(6 \%)$. At the same time as the educational programme began, the participants of the study started to receive a treatment based on inhaled steroids (94\%) and received oral steroids intermittently to treat asthma exacerbations $(76 \%)$.

Children with moderate asthma received 200-600 $\mu \mathrm{g}$. day $^{-1}$ of inhaled beclomethasone and children with severe asthma received 800-1500 $\mu \mathrm{g} \cdot \mathrm{day}^{-1}$. For asthma exacerbations a short course of oral prednisone was used $(1 \mathrm{mg}$. $\mathrm{kg}^{-1} \cdot$ day-1 $^{-1}$ for 5 days). Most asthma exacerbations were observed in the months of May-August. These are the months in São Paulo with lower temperatures and higher 
Table 1. - Use of antiasthmatic medication before and after the programme

\begin{tabular}{|c|c|c|}
\hline & Before & After \\
\hline \multicolumn{3}{|l|}{ Bronchodilators } \\
\hline Oral $\beta_{2}$-agonists & $47(94)$ & $(0)$ \\
\hline Oral theophylline & $33(66)$ & $0 \quad(0)$ \\
\hline Inhaled $\beta_{2}$-agonist & $6(12)$ & $50(100)$ \\
\hline Inhaled long acting $\beta_{2}$-agonist & $0 \quad(0)$ & $6(12)$ \\
\hline \multicolumn{3}{|l|}{ Preventative treatment } \\
\hline Ketotifen & $8(16)$ & (2) \\
\hline Chromoglycate & $4 \quad(8)$ & $1 \quad(2)$ \\
\hline Inhaled steroids & $3(6)$ & 47 (94) \\
\hline Total & $15(30)$ & $49(98)$ \\
\hline \multicolumn{3}{|l|}{ Oral steroids } \\
\hline Intermittently & $28(56)$ & $38(76)$ \\
\hline $\begin{array}{l}\text { Daily for }>3 \text { months before the } \\
\text { study }\end{array}$ & $\begin{array}{ll}0 & (0)\end{array}$ & \\
\hline $\begin{array}{l}\text { Daily for 3-4 months in the } \\
\text { beginning of the study }\end{array}$ & & $10 \quad(20)$ \\
\hline Daily at the end of the study & & (0) \\
\hline
\end{tabular}

Values are presented as number of subjects with percentages in parenthesis.

Table 2. - Sex, age range and asthma severity of participants

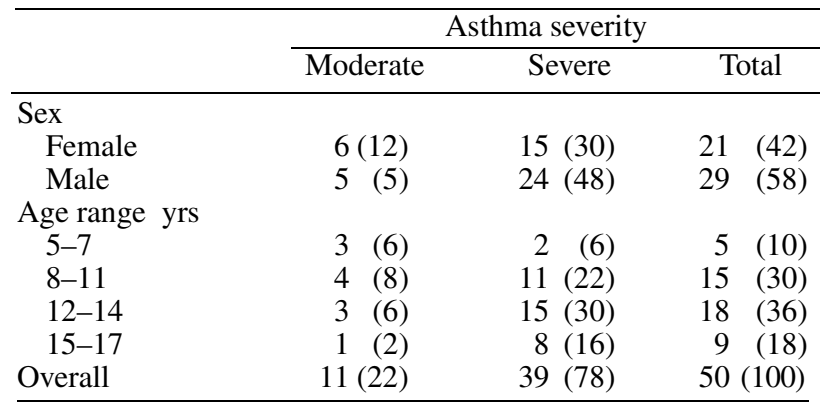

Values are presented as number of subjects with percentages in parenthesis.

levels of air pollution. Children with severe asthma received an average of one to two courses of oral prednisone each month, during this period. Children with moderate asthma needed three to four courses of oral prednisone a year. Ten children had very severe asthma and received, at the beginning of the programme, oral prednisone $1 \mathrm{mg} \cdot \mathrm{kg}^{-1}$ -day ${ }^{-1}$. The dose of prednisone was slowly reduced and inhaled beclomethasone was introduced, and 3-4 months were required to stop oral prednisone in these children. In the last months of the programme, no child was receiving oral prednisone continuously.

Table 3 shows the frequency of asthma symptoms and use of medical services before and after the programme. There was a high frequency of hospital admissions and emergency visits before the programme demonstrating that medical care for asthma was conducted in emergency rooms. In contrast, after the completion of the education programme, none of the children was often admitted to a hospital because of an asthma crisis and the number of visits to an emergency room decreased significantly. The children kept office appointments with the physician in an effort to avoid crises. Seventy-eight per cent of children had daily symptoms and $56 \%$ had severe attacks with cyanosis before the study, compared with none after the programme.
Table 3. - Asthma symptoms and use of medical services before and after the programme

\begin{tabular}{lrrrrr}
\hline & \multicolumn{2}{c}{ Before } & \multicolumn{2}{c}{ After } \\
\hline Hospital admissions & 18 & $(36)$ & & 50 & $(100)$ \\
0 & 11 & $(22)$ & & 0 & $(0)$ \\
$<3$ & 12 & $(24)$ & & $(0)$ \\
$3-6$ & 9 & $(18)$ & 0 & $(0)$ \\
$>6$ & 50 & $(100)$ & & 50 & $(100)$ \\
$\quad$ Total & & & & & \\
Emergency visits & 2 & $(4)$ & 44 & $(88)$ \\
0 & 8 & $(16)$ & 1 & $(2)$ \\
$2-6 \cdot y^{-1}$ & 10 & $(20)$ & 5 & $(10)$ \\
$7-12 \cdot$ yr $^{-1}$ & 30 & $(60)$ & 0 & $(0)$ \\
$>$ once a week & 50 & $(100)$ & 50 & $(100)$ \\
$\quad$ Total & 4 & $(8)$ & 0 & $(0)$ \\
Intensive care unit $_{\text {Daily symptoms }}$ & 38 & $(78)$ & 0 & $(0)$ \\
Severe attacks with cyanosis & 28 & $(56)$ & 0 & $(0)$ \\
\hline
\end{tabular}

Values are presented as number of subjects with percentages in parenthesis.

There was a significant decrease in both the asthma severity score and the asthma impairment score after the programme (figs. 1 and 2, p<0.0001). All participants showed a decrease in both indexes.

The activities mostly impaired by the disease were riding on a bicycle $(76 \%)$, playing with other children and pets $(78 \%)$, playing sports $(80 \%)$, walking uphill $(82 \%)$ and running (84\%). After the programme, only $24 \%$ and $32 \%$ of the parents reported some degree of impairment with playing with pets and running uphill, respectively.

When the participants were evaluated for proper MDI technique before the programme, only six children used MDI and none of them did it properly. After the programme 47 children used the MDI with a spacer device with adequate technique (scored 10). The three children who used the MDI without a spacer device achieved a score of 5 when evaluated for proper MDI technique.

Fifty parents answered the knowledge questionnaire. Before the programme only 12 had some information about asthma, mainly regarding triggers. After the programme, all parents answered all of the questions correctly, showing an increase in their knowledge about asthma.

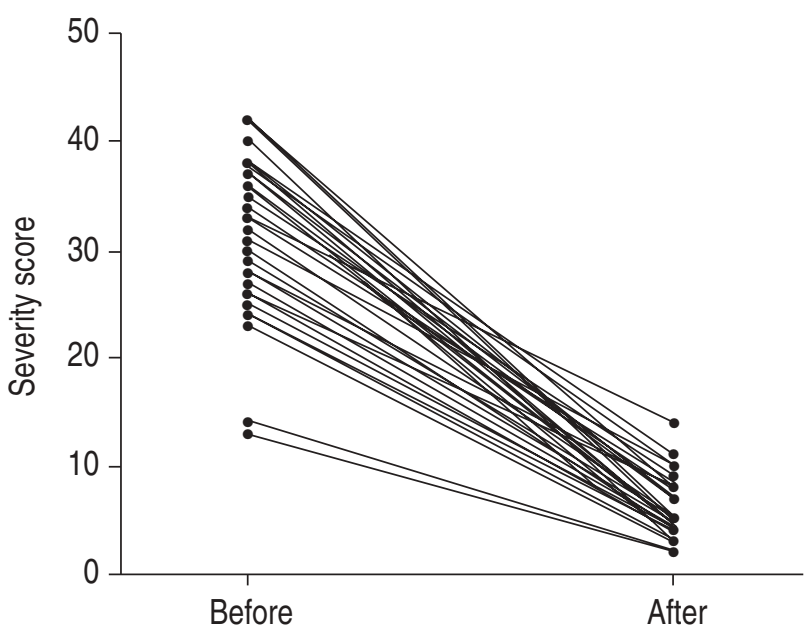

Fig. 1. - Asthma severity score evaluated before and 1 yr after the educational programme. Each line connects the values obtained in one child before and after the programme. There was a significant decrease in the asthma severity score in all 50 children studied $(\mathrm{p}<0.0001$, Wilcoxon signed rank test). 


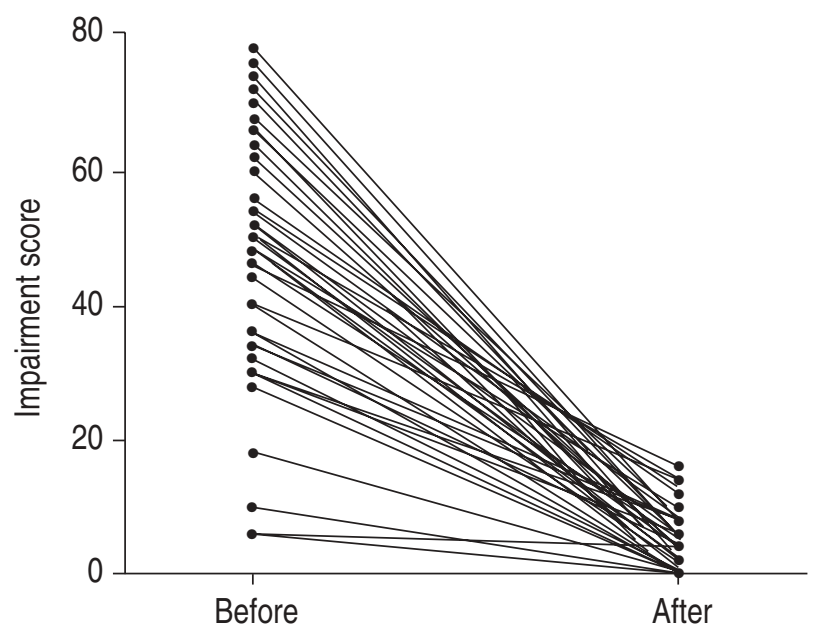

Fig. 2. - Asthma impairment score evaluated before and $1 \mathrm{yr}$ after the educational programme. Each line connects the values obtained in one child before and after the programme. All children studied showed a significant decrease in the impairment score ( $\mathrm{p}<0.0001$, Wilcoxon signed rank test).

\section{Discussion}

It is now well established that asthma is a chronic inflammatory disorder of the airways and that the treatment of asthma must include an anti-inflammatory drug, at least in patients with moderate or severe asthma. Anti-inflammatory drugs are now considered the maintenance or preventive therapy and bronchodilators have become rescue treatment or medications used to relieve the symptoms of asthma. Although more studies are needed to establish the safety of long-term use of inhaled corticosteroids in children, these drugs have been increasingly used as a first-line therapy in the management of moderate or severe asthma in children $[16,18,19]$.

Analysing the data, it became evident that most of the children who participated in this study were receiving inadequate medical care from their physicians. This was due to inappropriate prescription and no specific treatment plan. Although these children had moderate or severe asthma, they were mainly being treated with bronchodilators (only three received inhaled steroid on a regular basis; table 2). Crisis care in the emergency room was the major intervention. It was observed that $60 \%$ of participants had had to visit an emergency room more than once a week in the previous year. The major home intervention was an oral $\beta$-agonist and those who used a MDI did not know how to use it properly.

Despite several international workshops that produced recommendations for the treatment of asthma [16, 18, 19], many physicians in the city of São Paulo do not follow these recommendations. These findings, however, are not exclusive to developing countries, since the present observations are similar to those of LewIs et al. [15] in a clinical trial dealing with poor Hispanic children in Los Angeles, USA. Moreover, BousQuET et al. [20] who studied a nonselected population of adult patients with asthma, reported that among the patients with severe asthma, $85 \%$ of the patients from Paris and $60 \%$ from Montpellier were not receiving an anti-inflammatory treatment.

Lack of understanding or appreciation of the importance of a national programme for asthma control is proba- bly also responsible for the acceptance of a pattern of urgent and emergency care as the standard for management of childhood asthma. Deficits in primary care and financial barriers against purchasing medications are still problems in Brazil. São Paulo is a very large urban conglomerate (about 15 million inhabitants) with many medical specialists, but people with low incomes do not have easy access to this kind of professional support. Suboptimal management in low-income patients with asthma suggests a need for improvement throughout the healthcare system. It is easier to suggest guidelines for asthma management than to implement them and therefore achieve the desired results. In Brazil, people with low incomes have free access to a public system of primary and secondary (hospital) health services. However, outside hospital, people have to pay for most of their drug therapy, such as inhaled corticosteroids or $\beta$-agonists. The present programme resulted in a reduction in the cost of care of the asthmatic patients, since there was a decrease in the number of visits to emergency rooms and admissions to a hospital. However, there was an increase in the costs to the patient. A child with moderate or severe asthma received, respectively, $200-600$ or $800-1500 \mu \mathrm{g} \cdot$ day $^{-1}$ of beclomethasone. This costs, in Brazil, US\$10-40.month ${ }^{-1}$. The monthly income of the families that participated in this programme was US\$200-600. The cost of medication is an issue that must be addressed by healthcare providers in developing countries. However, an increase was observed in the income of some families after the programme since the mothers could start working as their children's health improved.

Previous studies have shown lower contact with and utilization of formal and professional health services in the USA among African-Americans [21-23], suggesting that other barriers to the use of medical services exist besides proximity to good care. The importance of such barriers was also shown in a study where asthma education alone did not reduce emergency-room use [24]. It was concluded that reducing emergency-room use requires more than changes in an individual's knowledge of asthma. In contrast, the present study showed a significant reduction in emergency-care use. This finding was probably due to better medical care, as well as the fact the parents learned to follow a preventive asthma care in a nonemergency situation, before the deterioration of their children's asthma. Ideally, ambulatory management for asthma should be such that respiratory status does not deteriorate to the point of repeated emergency-room visits and hospitalization. Darcy Vargas is a community hospital easily accessible to patients who live nearby, furthermore most of the employees also live in the same neighbourhood. Therefore, barriers to the access and continuity of medical care were not a problem for these families.

The educational programme presented here is only an adjuvant to good medical care and was not designed to replace adequate medications. Therefore, all participants received a specific treatment plan for their asthma and started to use preventive medications on a regular basis. With the help of this programme it was possible to obtain an excellent patient adherence to treatment and almost all patients learned how and when to use their medications correctly. Although the study was not a randomized clinical trial, a dramatic improvement in asthma control and quality of life could be demonstrated. As indicated in 
table 3, $1 \mathrm{yr}$ after the education programme significant reductions in the use of emergency departments and hospitalizations were observed. Similarly to previous studies $[12,13,15]$, this self-management programme emphasized atten-tion to mild symptoms that are often considered unimportant by these patients and their families. It is, therefore, considered very important to teach patients what they have to observe and which clues must be used to initiate self-management.

The combination of good medical care and an educational programme dramatically reduced the symptoms of asthma and significantly increased the quality of life. The costs of the asthma medical care with this programme were reduced since there was a significant decrease in emergency-room visits and hospital admissions. Initially the implementation of asthma management guidelines may lead to some increased costs in asthma care, but, with the expected improvements in asthma management, a net reduction in total health costs should result. This reduction in costs of medical care is especially important for developing countries where the resources available for health care are limited.

Appendix I: Questionnaire used to measure asthma severity

The same questions were made before treatment and $1 \mathrm{yr}$ after the programme.

1. Has your child been hospitalized for an asthmatic attack in the last 2 yrs?

yes (4); no (0)

How many times?

2. How often did he/she go to the emergency room in the last year?

did not go (0); 2-6 times a year (2); 7-12 times a year (4); more than once a month (6).

3 . When he/she goes to emergency room

he/she only needs bronchodilators (1)

he/she stays there for $>3 \mathrm{~h}$ receiving bronchodilators by nebulization (2)

he/she also receives other medications (3)

he/she also needs IV medications (4)

4. In the last 12 months, has your child had an asthmatic attack severe enough to cause cyanosis?

yes (4); no (0)

5 . Has your child been admitted to the intensive care unit by an asthmatic attack?

yes (4); no (0)

6. In the last 12 months, how often did your child have episodes of wheezing, cough or shortness of breath?

daily (4); weekly (3); one or two times a month (2); less than monthly $(1)$; never $(0)$

7. In the last 12 months, how often did your child awake at night with cough or wheezing?

most nights (4); 1-3 mornings.week ${ }^{-1}(3) ;<1$ night.week-1 (2); seldom (1); never (0)

8. In the last 12 months, how often was your child's wheezing troublesome in the morning?

most mornings (4); 1-3 mornings. week $^{-1}$ (3); <1 mornings. week $^{-1}(2)$; seldom (1); never (0)

9. In the last 12 months, how often were your child's activities affected or limited by cough or wheezing or shortness of breath? daily (4); weekly (3); one or two times a month (2); less than monthly (1); never (0)

10. In the last 12 months, has your child had an asthma attack that was severe enough to limit speech to only one or two words at a time between breaths? yes (4); no (0)

Appendix II: Questions to parents to assess their level of knowledge about asthma

1. What is asthma?

2. What are the things that trigger asthma symptoms?

3 . What can you do to avoid contact with these triggers?

4. What is a bronchodilator medicine and when should this medicine be used? Tell me the names of bronchodilators you know.

5. What is a controller medicine and when should this medicine be used? Tell me the names of controllers you know.

6. When do you know that your child's asthma is getting out of control? Which are the warning signs?

7. When do you have to take your child to the emergency room?

Appendix III: Asthma action plan (adapted from the International Consensus Report on Diagnosis and Treatment of Asthma. 1992 [16]).

Green zone: This is where you should be every day.

No daily symptoms of asthma

You are able to do your usual activities and sleep without having symptoms

Take these medicines: a) inhaled beclomethasone; dose: (lowest dose that maintains control of symptoms); when: regularly, twice a day; b) inhaled fenoterol or salbutamol, dose: $200 \mu \mathrm{g}$; when: p.r.n.

Follow your asthma trigger control plan to avoid things that bring on your asthma.

Yellow zone: This is not where you should be every day. You may be coughing, wheezing, feel short of breath, or feel like your chest is tight. These symptoms may keep you from usual activities or keep you from sleeping. You start to use your bronchodilator more than usual. If symptoms persist for more than three consecutive days, are increasing or if you start waking up with asthma at night, increase the dose of your controller medicine according to the following instructions: increase your inhaled corticosteroid up to $1500 \mu \mathrm{g}$; use your $\beta_{2}$-agonist p.r.n.

Let your doctor know if you keep going into the yellow zone.

Red zone: Medical alert.

You may be coughing, very short of breath and you may have trouble walking or talking.

You use your bronchodilator and don't get the same relief or its action lasts $<2 \mathrm{~h}$.

Start prednisone $1 \mathrm{mg} \cdot \mathrm{kg}^{-1} \cdot \mathrm{day}^{-1}$ (up to $40 \mathrm{mg} \cdot \mathrm{day}^{-1}$ ) and contact your doctor for follow-up instructions. If needed, you can repeat your inhaled $\beta_{2}$-agonist three times every 20-30 min. If you don't feel better go to the emergency room. Go to the hospital right away if any of these things are happening: your lips or fingernails are blue; you are 
struggling to breathe; or you don't feel any better after taking your bronchodilator

Note: The action plan is individualized as far as possible and the green zone depends on the level of asthma severity.

\section{References}

1. Burney PG, Chinn S, Rona RJ. Has the prevalence of asthma increased in children? Evidence from the national study of health and growth 1973-86. BMJ 1990; 300: 13061310.

2. Mitchell EA. Increasing prevalence of asthma in children. N Z Med J 1983; 96: 463-464.

3. Peat JK, van den Berg RH, Green WF, Mellis CM, Leeder SR, Woolcok AJ. Changing prevalence of asthma in Australian children. BMJ 1994; 308: 1591-1596.

4. Robertson CF, Bishop J, Sennhauser FH, Mallol J. International comparison of asthma prevalence in children: Australia, Switzerland, Chile. Pediatr Pulmonol 1993; 16(4): 219-226.

5. Gergen PJ, Mullally DI, Evans R III. National survey of prevalence of asthma among children in the United States 1976-1980. Pediatrics 1988; 81: 1-7.

6. Parcel GS, Gilman SC, Nader PR, Bunce H. A comparison of absentee rates of elementary school children with asthma and nonasthmatic schoolmates. Pediatrics 1979; 64: 878-881.

7. Taylor WR, Newacheck PW. Impact of childhood asthma on health. Pediatrics 1992; 90: 657-662.

8. National Center for Health Statistics. The National Ambulatory Care Survey, United States 1979. Summary Ser. 13, No. 66. Hyattsville, MD, Dept of Health and Human Services, 1982; DHHS Publication No. PHS 82-1727.

9. Asthma mortality and hospitalization among children and young adults. United States 1980-1993. Morb Mortal Wkly Rep 1996 May 3; 45(17): 350-353.

10. Klingelhofer EL, Gershwin ME. Asthma self-management programs: premises, not promises. J Asthma 1988; 25: 89-101.

11. Evans D, Mellins RB. Educational programs for children with asthma. Pediatrician 1991; 18: 317-323.
12. Lewis CE, Rachelesfsky GS, Lewis MA, de-la-Sota A, Kaplan M. A randomized trial of A.C.T. (asthma care training) for kids. Pediatrics 1984; 74: 478-486.

13. Lewis MA, de la Sota A, Rachelefsky G, Lewis CE, Quinones H, Richards W. ACT-Asthma control Y tratamiento pare ninos: a progress report. Health Educ Q 1987; 14 (3): 281-290.

14. Clark NM, Feldman CH, Evans D, Levison MJ, Wasilewski $\mathrm{Y}$, Mellins RB. The impact of health education on frequency and cost of health care use by low- income children with asthma. J Allergy Clin Immunol 1986; 78: 108-115.

15. Lewis MA, Rachelefsky G, Lewis CE, Leake B, Richards W. The termination of a randomized clinical trial for poor hispanic children. Arch Pediatr Adolesc Med 1994; 148: 364-367.

16. International Consensus Report on Diagnosis and Treatment of Asthma. NHLBI (Bethesda, MD, USA), 1992; Publication No. 92-3091.

17. Rosier MJ, Bishop J, Noleen T, Robertson CF, Carlin JB, Phelan PD. Measurement of functional severity of asthma in children. Am J Respir Crit Care Med 1994; 149(6): 1434 1441.

18. National Asthma Education Program. Guidelines for the Diagnosis and Management of Asthma. NIH (Bethesda, MD, USA), 1991; Publication No. 91: 3042.

19. Expert Panel. Report 2: Guidelines for the Treatment and Management of Asthma. NIH (Bethesda, MD, USA), 1997; Publication No. 97-4051-A.

20. Bousquet J, Knani J, Henry C, et al. Undertreatment in a nonselected population of adult patients with asthma. $J$ Allergy Clin Immunol 1996; 98: 514-521.

21. Sly R, O'Donnell R. Association of asthma mortality with medical specialist density. Ann Allergy 1992; 68: 340-344.

22. Blendon RJ, Aiken LH, Freeman HE, Corey CR. Access to medical care for black and white Americans: a matter of continuing concern. JAMA 1989; 261 (2): 278-281.

23. Mitchell RE, Barbarian OA, Hurley DJ. Problem solving, resource utilization, and community involvement in a black and white community. Am J Comm Psychol 1981; 9: 233246.

24. Shields M, Griffin K, McNabb W. The effect of a patient education program on emergency room use for inner-city children with asthma. Am J Public Health 1990; 80: 36-38. 